\title{
Characterization of Commercial Ceramic Adsorbents and its Application on Naphthenic Acids Removal of Petroleum Distillates
}

\author{
Juliana Pereira Silva*, Lilian Ferreira de Senna*, \\ Dalva Cristina Baptista do Lago a, Paulo Ferreira da Silva Jr., Elton Gonçalves Dias ${ }^{\mathrm{a}}$, \\ Marco Antônio Gaya de Figueiredo ${ }^{\text {a }}$ Sandra Shirley Ximenes Chiaro ${ }^{\text {b }}$ \\ anniversidade do Estado do Rio de Janeiro, Rua São Francisco Xavier, 524, \\ Pavilhão Haroldo Lisboa, sala 427, Maracanã, 20550-013 Rio de Janeiro - RJ, Brazil \\ ${ }^{\mathrm{b}}$ CENPES/PETROBRAS, Rua São Francisco Xavier, 524, \\ Pavilhão Haroldo Lisboa, sala 427, Maracanã, 20550-013 Rio de Janeiro - RJ, Brazil
}

Received: April 17, 2007; Revised: June 11, 2007

\begin{abstract}
The mixture of carboxylic acids present in petroleum oil and directly responsible for its acidity and corrosiveness in liquid phase during the refine process is denominated "naphthenic acids". These acids are also present in distilled fraction of petroleum, causing several problems in final products quality. A possible way to remove the carboxilic acids from petroleum distilled fractions is the adsorption in porous materials. However, the results obtained until now indicate that ion exchange resins would be the best adsorbents for this process, which would probably increase its cost. In this work, two commercial adsorbents (clay and activated alumina) were characterized by a set of physical-chemistry techniques and evaluated concerning their capacity of removing naphthenic acids from a light petroleum fraction. It was verified the influence of a thermal treatment previous to the adsorption in its physical-chemistry characteristics and its properties. A high reduction of the TAN values was verified in the residual oils from both adsorbent, although there was a competition among all the compounds present in the light oil fraction for the adsorption sites, which can be probably related to the thermal pre-treatment. These results were related to corrosion yield experiments, and it was observed that the adsorbent pretreatment also affected the reduction in corrosion yields for both alumina and clay.
\end{abstract}

Keywords: adsorption, petroleum derivatives, clay, alumina

\section{Introduction}

Naphthenic acids occur naturally in crude oils through all over the world. The percent in which they appear may vary according to their source. The Total Acid Number (TAN) indicates the amount of naphthenic acid present in oil. When naphthenic acid rich oils are processed in refineries, corrosion may occur. This type of attack is called "naphthenic acid corrosion", and is known since 1920's. Each TAN unity corresponds to a depreciation of US\$ 0.50 in the oil market ${ }^{1}$. Moreover, the oil derivatives produced can also contain naphthenic acids.

Several ways to solve this problem had been proposed, most of them based on case study. Oils blends, material changes, corrosion inhibitors, and naphthenic acid removal are the main purposes. This work proposes a low cost, simple and effective process for removing naphthenic acids from a light petroleum fraction using adsorption. Two commercial and easily available materials (clay and activated alumina) were characterized by several physical chemistry techniques, and then experienced as adsorbents, causing the reduction of both TAN and corrosion yield.

\section{Literature Review}

The term "naphtenic acids" is used, in general, for organic acids in petroleum oil and its derivatives. This term results from the monobasic carboxylic acids containing monocyclic structure. Nevertheless, it is possible the presence of compounds varying from low weight straight acids to complex ones formed by multiples rings of 5 or 6 carbon atoms, saturated or insaturated ${ }^{2}$. These compounds can even present in their structures other atoms or functions, like phenol, indol or tiophene ${ }^{3}$.

The most used method to quantify naphthenic acids in petroleum oil and its derivatives is the Total Acid Number (TAN), determined by titration of the sample against $\mathrm{KOH}$, using either potentiometric $(\text { ASTM D664) })^{4}$ or colorimetric (ASTM D974) $)^{5}$ method. Both methods allow the determination of the Strong Acid Number (SAN) and

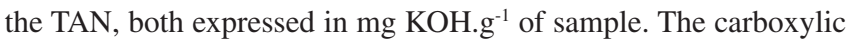
acids are detected in TAN, but not in SAN. As the majority of oil SAN result is negligible, the TAN is generally used as a measure of naphthenic acidity ${ }^{2,3}$.

However, it is known that the acidity of petroleum is not caused only by naphthenic acids: previous studies have showed that sulphur, nitrogen and aromatic compounds are also major contributors for the petroleum acidity ${ }^{3,6,7}$. The most important result on the presence of these acids in oil is corrosion, as shown earlier ${ }^{1}$. To solve this problem, there are several studies considering methods to minimize the corrosion caused by such acids under high temperatures. They include the substitution of equipment materials ${ }^{6}$, the locally injection of inhibitors in the affected areas ${ }^{2,6}$, and the removal of naphthenic acids by extraction or adsorption ${ }^{3,7-15}$. This last method presents low cost and will be detailed in this work. Moreover, it is important to point out that the recovered naphthenic salt can be used as catalysts, preservatives, corrosion inhibitors and emulsifiers ${ }^{3,7}$. 
The most used and effective process to remove naphthenic acids from oils is the liquid-liquid extraction, especially when using ammonia or alkali alcoholic solutions. However, these systems usually form stable emulsions ${ }^{7}$. Therefore, there are several proposals for the liquid-liquid extraction using different solvent systems ${ }^{8-13}$. As these acids are, in general, at low concentrations, an efficient treatment can be the use of adsorption processes. There are few processes reporting the removal of naphthenic acids from petroleum fractions using various adsorbents. Gillespie et al., describe a process to remove these acids from kerosene with a mixture of magnesium and aluminum oxides $^{14}$. The adsorption of naphthenic acids has already been reported on zeolites, aluminosilicates from catalyst manufacturing process waste, silica-gel, clays and ion-exchange resins. These acids can be recovered using polar solvents ${ }^{7,15}$. The best results were obtained for ion-exchange resins, which can make the process very expensive. This work proposes the use of low cost commercial adsorbents, such as clay and activated alumina, to remove naphthenic acids from a light petroleum fraction. This way, these materials were first characterized to understand their adsorption process. Moreover, the corrosion yield of mild steel immersed in the oil fraction, before and after the adsorption process, was determined and related to the TAN results.

\section{Experimental Methods}

\subsection{Adsorbents and light oil fraction}

The light oil fraction used in present work, as well as its density values, were kindly supplied by Petrobras - Petróleo Brasileiro S.A.. It was then characterized in terms of viscosity, sulfur and nitrogen contents, and total acid number (TAN). The adsorbents used were samples of clay and activated alumina. The clay sample is an acid bentonite from TONSIL series (TCO626G), manufactured by Süd Chemie. The alumina sample is Selexsorb CD, commercialized by Almatis. The adsorbents were characterized by Scanning Electron Microscopy (SEM), Temperature Programmed Desorption (TPD), Thermogravimetric Analysis (TGA) and X rays Fluorescence (XFR). The data concerning the superficial area were supplied by their respective manufacturers.

\subsection{Adsorbents characterization}

\subsubsection{Chemical analysis}

The chemical analysis of activated alumina was supplied by the manufacturer. The X rays Fluorescence (XRF) analysis of the clay was performed in CENPES - Petrobras.

\subsubsection{Temperature Programmed Desorption (TPD)}

The TPD analysis using either ammonia or carbon dioxide, were used for quantification of the acid and basic nature adsorption sites of the materials. The Selexsorb was analyzed by both ammonia $(2.91 \% \mathrm{~mol})$ and carbon dioxide $(4.79 \% \mathrm{~mol}) \mathrm{TPD}$. The TCO $626 \mathrm{G}$ was analyzed only by ammonia TPD, because of its acid nature. In all analysis, helium was used as the carrier gas $(30 \mathrm{~mL} / \mathrm{min})$.

Before every test, the adsorbents were pre-heated to $500{ }^{\circ} \mathrm{C}$ at $10{ }^{\circ} \mathrm{C} /$ min, keeping this temperature for 1 hour, under constant helium flow. After that, the reactor was cooled to room temperature while keeping the helium flow. Then, the system was ready to perform the TPD test.

For the carbon dioxide TPD, one adsorption at $50{ }^{\circ} \mathrm{C}$, followed by one desorption at the same temperature, was the initial procedure. The same procedure was repeated, and then the temperature was raised to $400{ }^{\circ} \mathrm{C}$ at $5^{\circ} \mathrm{C} / \mathrm{min}$. In the ammonia TPD, the temperatures used were $150{ }^{\circ} \mathrm{C}$ for the adsorption/desorption procedure and $500{ }^{\circ} \mathrm{C}$ at $10^{\circ} \mathrm{C} / \mathrm{min}$ for the final desorption.

\subsubsection{Thermogravimetric Analysis (TGA)}

The purpose of thermogravimetric experiments was to verify the existence of adsorbed substances that could interfere in naphthenic acids removal. The samples were heated to $950{ }^{\circ} \mathrm{C}$ at $10^{\circ} \mathrm{C} / \mathrm{min}$ in a Q50 V6.4 Build 193 TGA, using nitrogen at $100 \mathrm{~mL} / \mathrm{min}$.

Based on the TGA results, the adsorbents were submitted to a pretreatment, which consisted of a pre-heating in an oven for 4 hours at $150{ }^{\circ} \mathrm{C}$ and then cooled to room temperature before each adsorption tests. This way, any adsorbed compound (especially water) was removed, permitting to verify the effect of these compounds in the process.

\subsubsection{Scanning Electron Microscopy (SEM)}

For SEM analysis, the samples were recovered with a thin gold layer and then attached to the support with a conducting tip. The analysis was performed in high vacuum using a JEOL JSM 6460LD microscope. The samples were observed in secondary electron (SE) and backscattering electron (BSE) modes, using accelerate voltages of 15 and $20 \mathrm{kV}$, depending on the material.

\subsection{Light oil fraction characterization}

\subsubsection{Sulfur and nitrogen contents}

The sulfur content was determined by fluorescence, according to ASTM D 5453-00 ${ }^{16}$ method, while the nitrogen content was obtained by quimiluminescence, according to ASTM D 4629-02 ${ }^{17}$ Method. Both were determined using an Elemental Analyzer ANTEK 9000NS.

\subsubsection{Kinematic viscosity}

This property was determined according to ASTM D $445^{18}$ method using a Viscosity Analyzer INCONMAP Cannon-Fenske.

\subsubsection{Total Acid Number (TAN)}

It was quantified by potenciometric titration using potassium hidroxide $(\mathrm{KOH})$, according to ASTM D664 ${ }^{4}$ method, using a Mettler DL25 titrator.

\subsection{Adsorption kinetics}

The adsorption tests were made in similar ways for both adsorbents. The pretreatment and the oil/adsorbent mass ratio were tested. In each test, the oil and the adsorbent (with or without pre-treatment) were added simultaneously in six plastic bottles, using sufficient quantities to give the same oil/adsorbent ratio $(2: 1$ or $1: 1)$ in each bottle. Then, the bottles were adapted into a shaker TECNAL TE 420, was set at $200 \mathrm{rpm}$, at room temperature. One bottle was removed every two hours and its content was decanted. The solid was discharged in appropriated recipients and the liquid phase was analyzed.

\subsection{Corrosion tests}

The corrosion experiments were performed using the system described in Figure 1, in which a mild steel cupon of $9.80 \mathrm{~cm}^{2}$ was immersed in the oil to replicate the conditions for naphthenic corrosion in liquid phase. Before the experiments, the specimens were mechanically polished, degreased with a solution of sodium lauril sulfate at $80^{\circ} \mathrm{C}$ for 10 minutes, washed with deionised water and alcohol, and finally dried. Then, each sample was weighted and loaded into the system. The temperature was raised until $240{ }^{\circ} \mathrm{C}$ for 20 minutes and kept at this value for 3 hours. After cooling for 30 minutes, the system was opened and the cupon was removed, washed only with deionised water, and dried. The sample was then immersed in Clark 
solution for 4 minutes, washed with deionised water and alcohol, dried and weighted. The corrosion rate (CR) was measured based on the weight loss, as shown in Equation $1^{19}$.

$$
\mathrm{CR}=\frac{\left(\mathrm{m}_{\mathrm{i}}-\mathrm{m}_{\mathrm{f}}\right) \times \mathrm{K}}{\mathrm{t} \times \rho \times \mathrm{A}}
$$

where, $m_{i}$ and $m_{f}$ are the initial and final mass weighted, respectively, $t$ is the time kept at the experiment temperature, $\rho$ is the specimen density (7.86 g. $\mathrm{cm}^{-3}$ for mild steel), and A is the exposed cupon area. The constant $\mathrm{K}=8.76 \times 10^{4}$ and was included to permit the result conversion to $(\mathrm{mm} / \text { year })^{19}$.

\section{Results and Discussion}

\subsection{Adsorbents characterization}

The chemical composition presented in Table 1 was obtained by $\mathrm{X}$ rays Fluorescence analysis (FRX). The activated alumina chemical composition indicates that the material is essentially alumina, with silica and iron oxide traces. The clay used in this work is an acid clay, probably originated from a calcium bentonite, since its composition was similar to that shown by Sun Kou et al. ${ }^{20}$.

Table 2 shows the surface area and TPD results. The alumina presents larger surface area and greater number of basic adsorption sites. Clay samples also present large surface areas, although smaller than the alumina ones, and smaller number of acid sites than alumina. No TPD tests for basic sites were performed for the clay samples, due to their acid characteristic.

The results of thermogravimetric analysis were similar for both adsorbents, showing an intense desorption peak in approximately $150{ }^{\circ} \mathrm{C}$ (not shown), which was related to water loss ${ }^{21,22}$. This way, that was the temperature used in the previous thermal treatment used

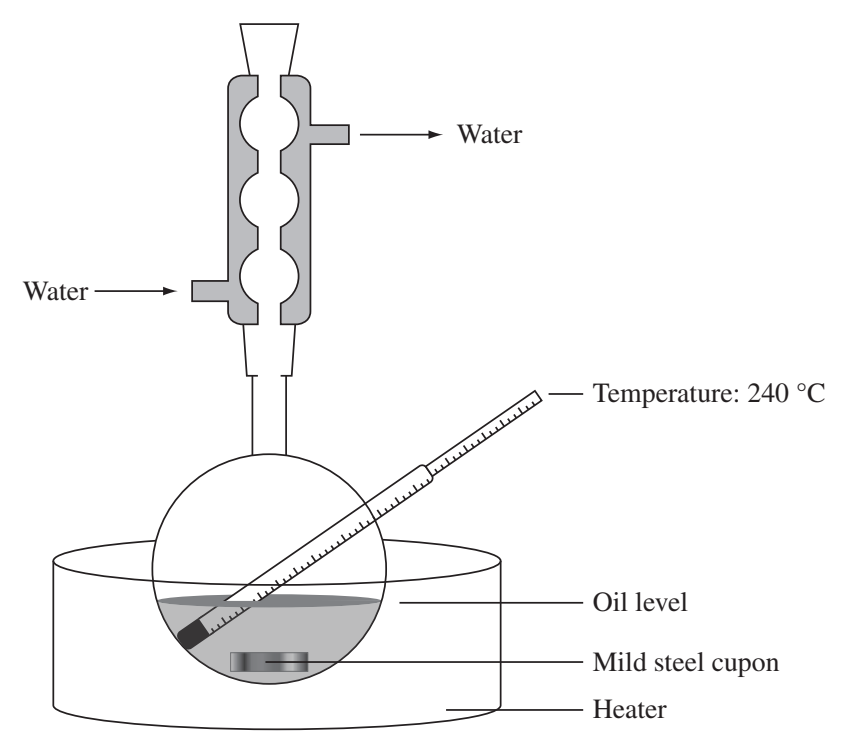

Figure 1. Corrosion test system. for both adsorbents. The time for thermal treatment ( 4 hours) was chosen based upon previous results for adsorption removal of sulfur and nitrogen compounds using the same adsorbents.

Distinct morphologies between clay and alumina were observed (Figure 2). The clay structure is lamellar (Figures $2 \mathrm{a}$ and $2 \mathrm{~b}$ ), while the alumina surface is more regular and homogeneous, with granular structures (Figures 2c and 2d). Applied thermal treatment did not seem to modify their morphologies significantly.

The irregular and lamellar topography of the clay (Figure 2a) became less compact in the thermically treated sample (Figure $2 b$ ). For activated alumina (Figure 2c), some clusters were observed in the most external layer, while small size grains were noted in its internal surface. A growth in the internal grain size was verified after the thermal treatment, increasing the material porosity (Figure 2d).

\subsection{Oil characterization}

The oil used in the experiments was a neutral and light fraction of petroleum, whose main characteristics are presented in Table 3.

It is very important to notice the high content of sulfur and nitrogen compounds presents in the oil sample which will also compete with naphthenic acids for the adsorption sites of both clay and activated alumina. Moreover, sulfur and aromatics compounds can also contribute for the total acidity of the oil.

\subsection{Adsorption kinetics}

In order to verify the possibility of using the studied materials as adsorbents in naphthenic acids removal process, adsorption kinetics were plotted for both clay and activated alumina. The experiments were performed with and without previous thermal treatment (Figure 3) and containing two different oil/adsorbent mass ratios (Figure 4).

Initially, the influence of the previous thermal treatment was

Table 2. Surface Characterization of the Adsorbents.

\begin{tabular}{lcc}
\hline & TCO 626G & Selexsorb CD 1/8 \\
\hline Surface area $\left(\mathrm{m}^{2} / \mathrm{g}\right)$ & 270 & 411 \\
Weak basic adsorption & - & 324.1 \\
sites $\left(\mu \mathrm{mol} \cdot \mathrm{g}^{-1}\right)$ & & 68.5 \\
$\begin{array}{l}\text { Strong basic adsorption } \\
\text { sites }\left(\mu \mathrm{mol} . \mathrm{g}^{-1}\right)\end{array}$ & - & 694.1 \\
$\begin{array}{l}\text { Weak acid adsorption } \\
\text { sites }\left(\mu \mathrm{mol.g} \mathrm{g}^{-1}\right)\end{array}$ & 280.9 & \\
$\begin{array}{l}\text { Strong acid adsorption } \\
\text { sites }\left(\mu \mathrm{mol.g} \mathrm{g}^{-1}\right)\end{array}$ & 78.2 & 299.3 \\
\hline
\end{tabular}

Table 3. Oil characterization

\begin{tabular}{lc}
\hline \multicolumn{1}{c}{ Density $\left(\mathrm{kg} . \mathrm{m}^{-3}\right)$} & 930 \\
\hline Kinematic viscosity $40^{\circ} \mathrm{C}\left(\mathrm{m}^{2} / \mathrm{s}\right)$ & $36.24 \times 10^{-4}$ \\
Nitrogen content $(\mathrm{ppm})$ & 1212.39 \\
Sulfur content $(\mathrm{ppm})$ & 3808.39 \\
TAN $\left(\mathrm{mg} \mathrm{KOH.g^{-1 }}\right.$ sample) & 1.17 \\
\hline
\end{tabular}

Table 1. Chemical Composition of the Adsorbents (\% m/m).

\begin{tabular}{lccccccccccc}
\hline & $\mathrm{Fe}_{2} \mathrm{O}_{3}$ & $\mathrm{Mn}_{2} \mathrm{O}_{3}$ & $\mathrm{TiO}_{2}$ & $\mathrm{CaO}$ & $\mathrm{K}_{2} \mathrm{O}$ & $\mathrm{Al}_{2} \mathrm{O}_{3}$ & $\mathrm{SiO}_{2}$ & $\mathrm{P}_{2} \mathrm{O}_{5}$ & $\mathrm{MgO}^{2}$ & $\mathrm{Na}_{2} \mathrm{O}$ & $\mathrm{LOI}$ \\
\hline TCO 626G & 1.78 & 0.04 & 0.22 & 1.55 & 0.55 & 12.22 & 54.75 & 0.01 & 4.62 & 0.22 & - \\
Selexsorb & 0.02 & - & - & - & - & 95.1 & 0.02 & - & - & 0.3 & 4.5 \\
\hline
\end{tabular}




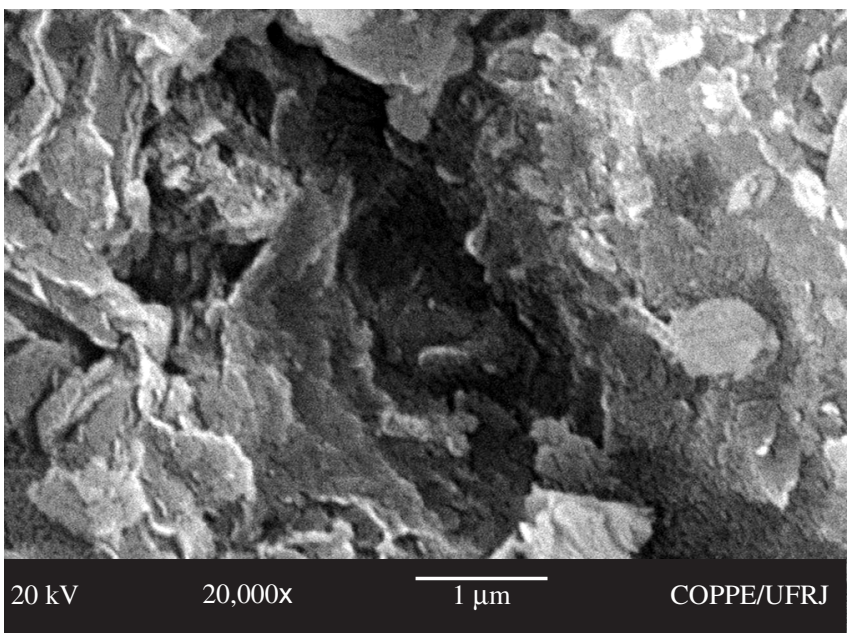

(a)

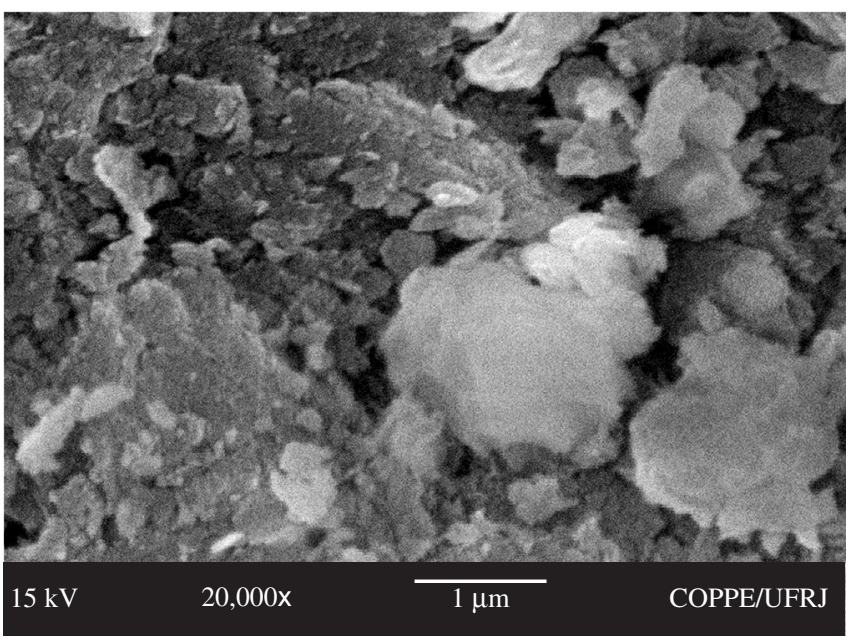

(b)

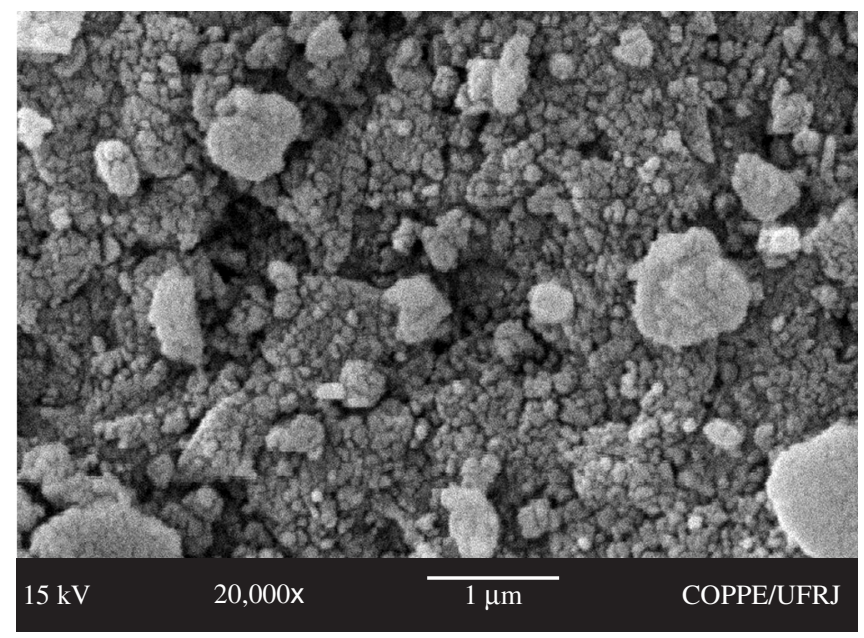

(c)

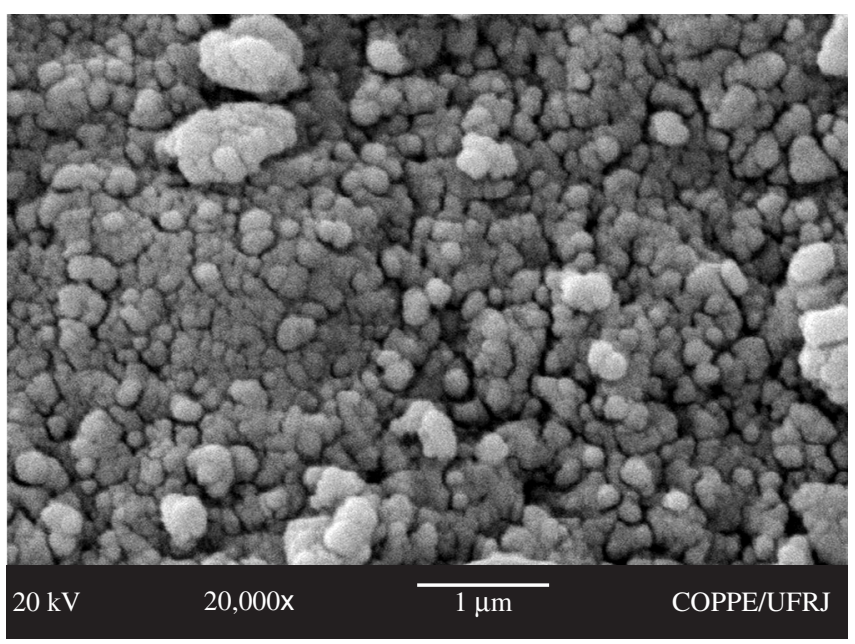

(d)

Figure 2. Effect of thermal treatment on the adsorbents morphology: a) TCO 626G clay without thermal treatment; b) TCO 626G clay with thermal treatment; c) Selexsorb CD alumina without thermal treatment; and d) Selexsorb CD alumina with thermal treatment.

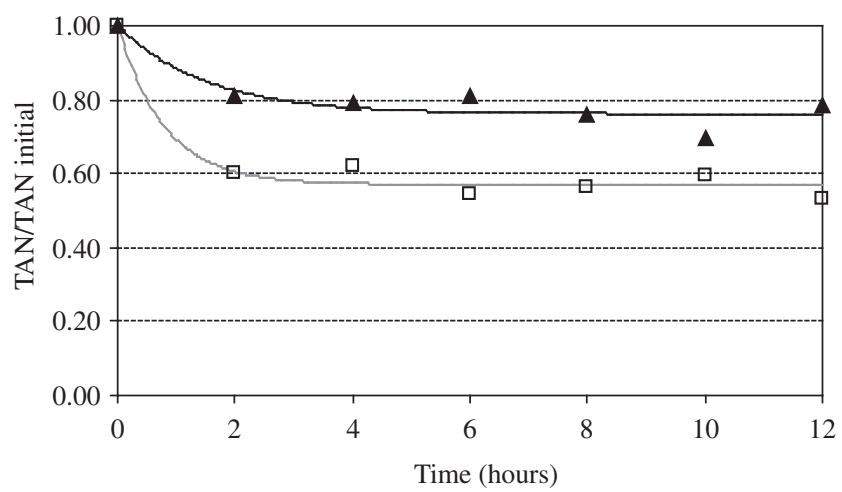

(a)

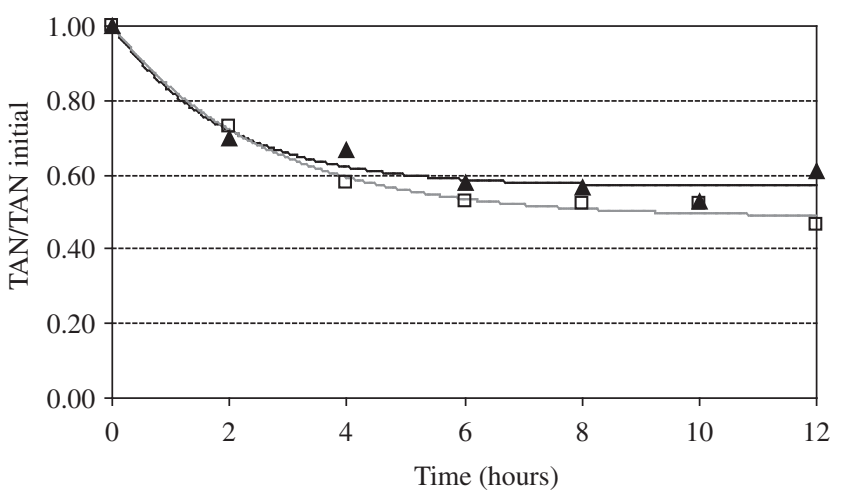

(b)

$\square-$ With thermal pre-treatment $\rightarrow-$ Without thermal pre-treatment

Figure 3. Adsorption kinetics curves. a) TCO 626G clay; and b) Selexsorb CD alumina. 
analyzed. In these experiments, all tests were carried out in systems with oil/adsorbent ratio 2:1. It was verified that the adsorption process in clay was more effective with the pre-treated adsorbent (Figure 3a). In opposition, there was almost no alteration in the adsorption curves using activated alumina, with or without previous thermal treatment (Figure 3b).

The effect of the oil/adsorbent ratio was compared in experiments where all tests were carried out with the previous thermal treatment. This condition was chosen based on the clay results presented in Figure $3 \mathrm{a}$, since this pre-treatment caused few variations for the experiments performed with activated alumina. The final adsorption curve showed almost no difference between the two ratios studied in clay tests, although kinetics were faster in the test containing small amount of adsorbent (Figure 4a). On the other hand, the adsorption process for activated alumina (Figure $4 \mathrm{~b}$ ) performed in 1:1 oil/adsorbent ratio was more effective, while the kinetics seemed to be similar, irrespective the oil/adsorbent ratio used.

Based on Figure 4, it is possible to see that the equilibrium condition was reached after 8 hours of adsorption, in all adsorption processes studied. The TAN value for equilibrium was then calculated as the mean of the three last points of the kinetics curve, and the percent of TAN reduction was calculated. Results are shown in Table 4, and it can be seen that the more effective reduction was obtained with activated alumina experiments.

The adsorption process in clay involves its great surface area and the presence of a negative global charge in its surface, in virtue of the isomorphic replacement of cations in the crystalline net of the mineral. This charge is, generally balanced for the adsorption of inorganic cations (for example, $\mathrm{H}^{+}, \mathrm{Na}^{+}, \mathrm{Ca}^{2+}$ ) in the internal and external surfaces of material ${ }^{23}$. The presence of the negative surface charge also makes the clay an excellent adsorbent for organic cations. In the present work, it was used a clay (bentonite) activated with organic acids to increase its surface area. The adsorptive properties of these activated clays depends on the chemical nature of the surface, and the adsorption process is influenced by electrostatic interation between adsorbate molecules and adsorption sites on clay surface, the nature of the exchangeable ion located in the interlayer, and the range of hydratation of the positive ion ${ }^{24}$. Polar molecules or polarizable ones are well adsorbed by these clays ${ }^{22}$. This could favor that acid composites, as naphthenic ones, could be attracted for the negative charge layers of the clay and then removed from oil. These acids can be ionizated or bonded in hydrogen bridges inside the oil. However, new experiments must be performed to reach a final conclusion about this topic.

On the other hand, alumina presents great surface area and its global surface charge is positive, what would favor the adsorption of negative charged composites, through an electrostatic interaction ${ }^{25}$. This could lead to the assumption that the highest reduction of TAN values, obtained with alumina, may result from the adsorption of naphthenic acid totally dissociated. However, as it is a non-aqueous environment, it is not possible to discard the probability of the adsorption process also occurs through interactions between molecules in the acid form and the weak basic sites present in great amount in alumina. Moreover, it is important to point out that, as this is a real

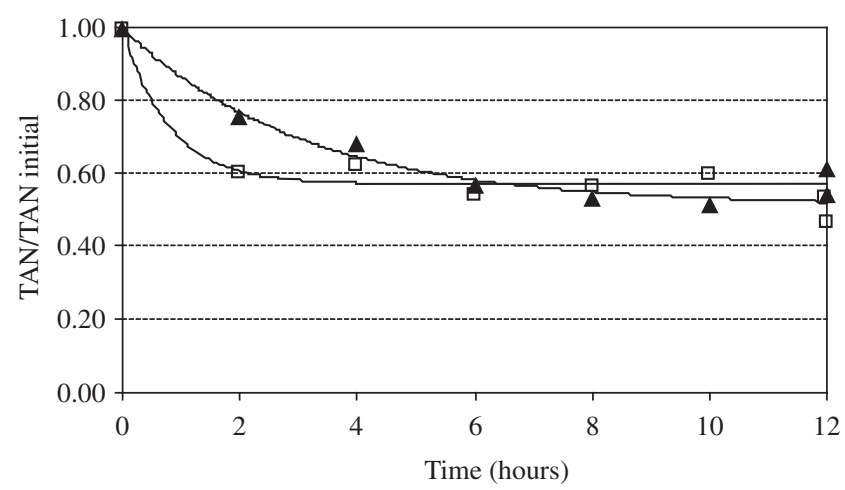

(a)

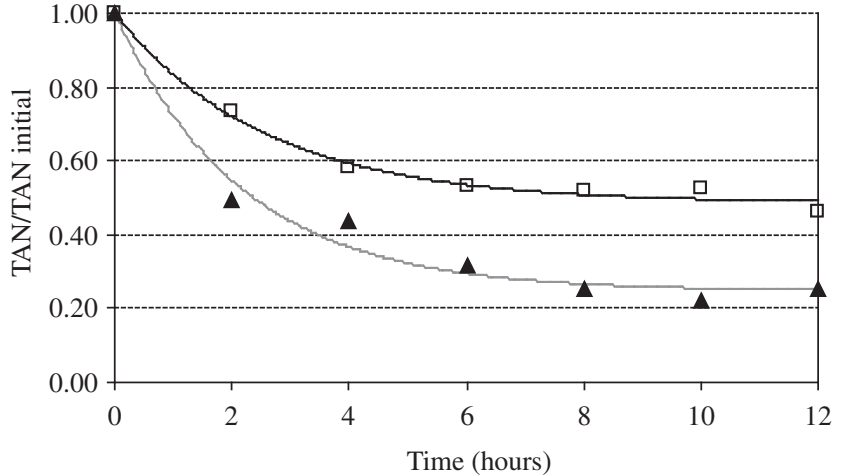

(b)

Oil/adsorbent mass ratio:

$\longrightarrow$ Mass ratio $=1 \quad \square$ Mass ratio $=2$

Figure 4. Adsorption kinetics curves varying oil/adsorbent mass ratio. a) TCO 626G clay; and b) Selexsorb CD alumina.

Table 4. Results of TAN and CR reduction.

\begin{tabular}{|c|c|c|c|c|c|c|}
\hline \multirow[b]{2}{*}{ Thermal treatment } & \multicolumn{3}{|c|}{ TCO 626G } & \multicolumn{3}{|c|}{ Selexsorb CD } \\
\hline & Yes & Yes & No & Yes & Yes & No \\
\hline Oil/Adsorbent ratio & $1: 1$ & $2: 1$ & $2: 1$ & $1: 1$ & $2: 1$ & $2: 1$ \\
\hline $\mathrm{TAN}_{\text {initial }}$ & 1.17 & 1.17 & 1.17 & 1.17 & 1.17 & 1.17 \\
\hline $\mathrm{TAN}_{\text {equilibrium }}$ & 0.620 & 0.659 & 0.871 & 0.283 & 0.586 & 0.661 \\
\hline TAN Reduction (\%) & 46.9 & 43.5 & 25.3 & 75.7 & 49.8 & 43.3 \\
\hline Initial corrosion (mm/year) & 0.761 & 0.761 & 0.761 & 0.761 & 0.761 & 0.761 \\
\hline Final corrosion (mm/year) & - & 0.113 & 0.125 & 0.187 & 0.352 & 0.010 \\
\hline $\mathrm{CR}$ reduction $(\%)$ & - & 85.2 & 83.6 & 75.4 & 53.7 & 98.7 \\
\hline
\end{tabular}


sample, naphthenic acids of differentiated force is possibly present in the oil and can be adsorbed by distinct processes. In addition, other compounds present in the oil can also be adsorbed, contributing for the final TAN value found in each experiment.

\subsection{Corrosion tests}

The results of the corrosion tests are also presented in Table 4, for the experiments performed with oil samples after the adsorption processes with both clay and activated alumina. It can be seen that, for thermally pre-treated Selexsorb, the increase in the oil/adsorbent ratio decreases both the TAN and the CR reduction, showing a direct relationship between TAN and CR. However, comparing these results with those of the oil obtained from the Selexsorb without thermal treatment at oil/adsorbent ratio 2:1, the relationship is inversed. In fact, the highest reduction in corrosion rate was obtained in this condition. Concerning the oils obtained from clay adsorption, the pre-treatment causes a higher TAN reduction, which is not followed by the CR results.

Reminding Table 3, it is important to know that a real sample also contains sulfur, nitrogen and aromatic compounds other than the naphthenic acids. Therefore, there is probably a competition for the adsorption sites of the adsorbers tested. Aromatic compounds and inorganic acids, such as $\mathrm{H}_{2} \mathrm{~S}$, can contribute to the TAN values. Moreover, the naphthenic acid corrosion mechanism can be modified in the presence of sulfur compounds, as shown by the following reactions ${ }^{26}$.

$$
\begin{aligned}
& \mathrm{Fe}+2 \mathrm{RCOOH} \rightarrow \mathrm{Fe}(\mathrm{RCOO})_{2}+\mathrm{H}_{2} \\
& \mathrm{Fe}+\mathrm{R} " \mathrm{SH} \rightarrow \mathrm{FeS}+\mathrm{H}_{2} \\
& \mathrm{Fe}(\mathrm{RCOO})_{2}+\mathrm{R} " \mathrm{SH} \rightarrow \mathrm{FeS}+2 \mathrm{RCOOR} "
\end{aligned}
$$

where R" can be hydrogen or any organic chair. Other sulfur compounds, as sulfonic acids, can also be present in the oil. The iron sulfide, FeS, is not soluble in oil and a protector film is formed, decreasing the corrosion process. On the other hand, the, $\mathrm{Fe}(\mathrm{RCOO})_{2}$, is soluble in oil and the metal corrosion increases. Furthermore, the naphthenic acid can be recovered by a reaction between the iron naphthenate and the sulfur compound. Therefore, there is an intimate relationship between the amount of sulfur compounds and the corrosion rate in oils also containing naphthenic acids. Thus, if the thermal pre-treatment favors the adsorption of sulfur compounds, comparing to naphthenic acids, the residual oil would be rich in these acids and poor in sulfur compounds decreasing the formation of the protecting FeS film. This difference in adsorption capacity with and without a previous thermal treatment has been noted for nitrogen compounds ${ }^{27}$. In consequence, the residual oil from an adsorption process using Selexsorb without thermal treatment could probably contain more sulfur compounds, increasing the formation of FeS films and decreasing the CR.

The adsoption process of the compounds other than naphthenic acids with clay is also favored, mainly for the pre-treatment conditions. However, the decrease in TAN was smaller than that obtained with the activated alumina in the same conditions, although the CR reduction was higher. The clay used in this work was an acid bentonite, which are usually used as oil bleaches ${ }^{22}$. Therefore, aromatic color compounds present in the oil can be preferentially adsorbed when compared to naphthenic acids or even sulfur compounds. This could probably explain both the TAN and the CR results.

\section{Conclusions}

Commercial adsorbents (TCO 626G clay and Selexsorb CD alumina) had been characterized by several physical-chemistry techniques and successfully applied in naphthenic acid removal in a real oil sample. The effect of thermal treatment in the clay significantly influenced the adsorption of acid composites of the oil. On the other hand, the effect of the oil/adsorbent ratio in the systems using this adsorbent was not intense. An opposition effect was verified for the residual oils from Selexsorb. There was a competition among all the compounds present in the light oil fraction for the adsorption sites, which can be probably related to the thermal pre-treatment.

It was observed that the great negatively (clay) or positively (alumina) charged surface areas can contribute for the adsorption of the naphthenic acids, and cause the reduction of the final values of TAN. Moreover, the effect of great amount of basic weak sites present in activated alumina may be added to the explanation concerning the higher reduction of TAN verified when this adsorbent was used in the experiment. On the other hand, the smaller TAN reduction in clay adsorption process could probably be supported in the fact that acid bentonites are usually used as oil bleaches, which can favor the adsoption of aromatic color compounds and decrease the adsorption of others compound, mainly sulfur compounds and naphthenic acids.

There was a reduction in the corrosion rate $(\mathrm{CR})$ of the mild steel cupons in the residual oils originated from the adsorption processes with both adsorbents. For the Selexorb process, the oil/adsorbent ratio affected the $\mathrm{CR}$ reduction at the same extent as the TAN reduction. However, the previous thermal treatment decreased the (CR) reduction, probably due to a higher sulfur compound removal. On the other hand, the pre-treatment caused almost no differences in the $\mathrm{CR}$ reduction for the oils after the clay adsorption process.

\section{Acknowledgments}

The authors thank to CAPES and UERJ for the financial aid, to Petrobras for the donation of the oil derivative samples and the FRX analysis, to LETPP/UERJ for the sulfur and nitrogen content analyses, and to Instruments' Laboratory of IQ/UERJ for the TGA analyses.

\section{References}

1. Albuquerque FC, Cintra RH, Silva MT, Braga CMS, Silva APO, Andrade, GH, Moura BR, Pereira RCL, Guimarães RCL, Silva PN. Estudo de Metodologias para determinação de ácidos naftênicos de petróleos nacionais. Anais of Congresso Brasileiro de $P \& D$ em Petróleo e Gás, Salvador, paper 0259, 2005.

2. Bruyn HJ. Naphthenic Acid Corrosion in Synthetic Fuels Production. Anais of Corrosion NACExpo 98, San Diego, paper 576, 1998.

3. Clemente JS, Fedorak PM. A review of the occurrence, analyses, toxicity, and biodegradation of naphtenic acids. Chemosphere. 2005; 60:585-600.

4. ASTM D664-04, Standard Test Method for Acid Number of Petroleum Products by Potentiometric Titration. ASTM International.

5. ASTM D974-04, Standard Test Method for Acid and Base Number by Color-Indicator Titration, ASTM International.

6. Babaian-Kibala, E. Phosphate ester inhibitors solve naphthenic acid corrosion problems. Oil \& Gas Journal, 1994; 92:31-35.

7. Gaikar VG, Maiti D. Adsorptive recovery of naphthenic acids using ionexchange resins. Reactive \& Functional Polymers, 1996; 31:155-164.

8. Varadaraj R, Pugel TM, Savage DW. Removal of Naphthtenic acids in crude oils and distillates. Exxon Research and Engineering Co. (Florham Park, NJ). US Patent No. 6.096.196, 27 mar. 1998, 1 ago. 2000.

9. Greaney MA. Method for reducing the naphthenic acid content of crude oil and fractions. Exxonmobil Research and Engineering Company (Annandale, NJ). US Patent No. 6.531.055 B1, 18 abr. 2000, 11 mar. 2003.

10. Sartori G, Savage DW, Olmstead WN, Robbins WK, Dalrymple DC, Ballinger BH. Process for treatment of petroleum acids with ammonia. Exxon Research and Engineering Company (Annandale, NJ). US Patent No. 6.258.258 B1, 21 set. 1999, 10 jul. 2001. 
11. Gorbaty ML, Martella DJ, Sartori G, Savage DW, Ballinger BH, Blum SC, Anderson MP, Ramanarayanan TA. Process for neutralization of petroleum acids using overbased detergents. Exxon Research and Engineering Co. (Florham Park, NJ). US Patent No. 6.054.042, 3 ago. 1998, 25 abr. 2000

12. Sartori G, Savage DW, Gorbaty ML, Ballinger BH. Process for neutralization of petroleum acids using alkali metal trialkylsilanolates. Exxon Research and Engineering Company (Florham Park, NJ). US Patent No. 5.643.439, 25 ago. 1995,1 jul. 1997.

13. Danzik, M. Process for removing naphthenic acids from petroleum distillates. Chevron Research Company (San Francisco, CA). US Patent No. 4.634.519, 11 jun. 1985, 6 jan. 1987.

14. Gillespie RD, Arena BJ. Naphthenic acid removal as an adjunct to liquid hydrocarbon sweetening. UOP (Des Plaines, IL). US Patent No. 5.389.240, 2 ago. 1993, 14 fev. 1995.

15. Zou L, Han B, Yan H, Kaperski KL, Xu Y, Hepler LG. Enthalpy of Adsorption and Isotherms for Adsorption of Naphtenic Acid onto Clays. Journal of Colloid and Interface Science, 1997; 190:472-475.

16. ASTM D5453-00. Standard Test Method for Determination of Total Sulfur in Light Hydrocarbons, Motor Fuels and Oils by Ultraviolet Fluorescence, ASTM International.

17. ASTM D4629-02, Standard Test Method for Trace Nitrogen in Liquid Petroleum Hydrocarbons by Syringe/Inlet Oxidative Combustion and Chemiluminescence Detection, ASTM International.

18. ASTM D445-06, Standard Test Method for Kinematic VISCOSITY of Transparent and Opaque Liquids (and Calculation of Dynamic VISCOSITY), ASTM International.
19. Carvalho LJ. Estudo do comportamento do nióbio em presença de petróleo com elevado índice de acidez. [Tese de Mestrado]. Universidade Federal do Rio de Janeiro, 1998.

20. Sun Kou MR, Volzone C, Sapag K. Adsorbentes em la solucion de algunos problemas ambientales. Chapter 10, p. 165-192, Cyted, Spain, 2004.

21. Silva JP. Estudo da adsorção de ácidos naftênicos a partir de correntes de hidrocarbonetos. [Tese de Mestrado]. Universidade do Estado do Rio de Janeiro; 2007.

22. Baraúna OS. Processo de adsorção de pigmentos de Óleo vegetal com argilas esmectíticas ácido-ativadas, Tese de Doutorado, UNICAMP, 2006.

23. Gürses A, Dograr Ç, Yalçin M, Açikyildiz M, Bayrak R, Karaca S. Journal of Hazardous Materials, B131, p. 217-228, 2006.

24. Alves RW. Extração de Corantes de Urucum por Processos Adsortivos utilizando argilas comerciais e Colloidal Gas Aphrons. [Tese de Doutorado]. Universidade Federal de Santa Catarina, 2005.

25. Lorphensri O, Intravijit J, Sabatini DA, Kibbey TCG, Osathaphan K. Saiwan C. Sorption of acetaminophen, 17a-ethynyl estradiol, nalidixic acid, and norfloxacin to silica, alumina, and a hydrophobic médium. Water Research. 2006; 40:1481-1491.

26. Yépez O. Influence of different sulfur components on corrosion due to naphthenic acid. Fuel, 2005; 84:97-104.

27. Figueiredo MAG, Zotin FMZ, Silva Jr PF, Meirelles SL, Corrêa HL, Pinto BE, Ramos MS, Pinto RR, Chiaro SSX. Proceedings of the $2^{\text {nd }}$ Mercorsur Congress on Chemical Engineering (EMPROMER), Costa Verde, RJ, CR-ROM, Agosto/2004. 